\title{
Nuclear data measurement and compilation for thin layer activation
}

\author{
F. Ditrói ${ }^{\mathrm{a}}$, S. Takács, and F. Tárkányi \\ Institute of Nuclear Research of the Hungarian Academy of Sciences, Debrecen, Hungary
}

\begin{abstract}
The Thin Layer Activation method (TLA) is widely used for wear, corrosion and erosion measurements by using medium energy charged particle accelerators. To accomplish a TLA experiment and calculate the amount of wear by using the nuclear tracing technique it is necessary to know the accurate excitation functions of the nuclear reactions in question as well as the nuclear data (half-life, $\gamma$-energies, etc.) of the produced tracer isotopes. In the framework of a systematic study a series of elements which may occur as common construction material have been investigated.
\end{abstract}

\section{Introduction}

The TLA technique is an accurate tool for wear measurements, when the equipment to be investigated is running and a disassembly/reassembly would strongly influence the result [1-3]. The measurement requires the knowledge of nuclear reactions in question [4-7] especially a reliable database of charged particle induced nuclear reactions.

The investigated elements/materials are: boron $[8,9]$, beryllium [10], aluminum, chromium, copper [15], iron $[17,19]$, molybdenum [25], niobium [11,16], nickel, titanium [12], tungsten [20,36], zinc [22,27], cadmium [34], iridium [28,36], platinum [23,24,31], silver [29,37], tin [33], palladium [38], lead [39], zirconium [21], yttrium [30], rubidium $[13,14]$ and tantalum $[18,26]$. The nuclear reactions investigated cover the most common light particle induced reactions available at medium energy accelerators, such as proton, deuteron, ${ }^{3} \mathrm{He}$ and alpha particle induced reactions. The irradiations have been performed in the framework of an international cooperation making possible the use of accelerators of different energy ranges up to $80 \mathrm{MeV}$ proton and $50 \mathrm{MeV}$ deuteron energy. The measured excitation functions have been plotted and compared with the literature data. To provide useful practical data yield curves were also deduced from the recommended excitation functions and compared with measured yields from other authors. In several cases activity versus depth distribution curves were also calculated as a direct tool to measure the surface wear of different materials [32].

\section{Experimental}

The irradiations were performed on the MGC-20E cyclotron in Debrecen, Hungary (up to $18 \mathrm{MeV}$ p), on the same type of cyclotron in Turku, Finland, on the CGR 560 cyclotron at the Vrije Universiteit Brussels, Belgium (up to $40 \mathrm{MeV}$ p) and on the AVF cyclotron at the Tohoku University, CYRIC, Sendai, Japan (up to $70 \mathrm{MeV}$ p). For the irradiations the well known stacked foil technique was used, where also monitor foils were inserted along the stack. The monitor reaction was

\footnotetext{
${ }^{a}$ Presenting author, e-mail: ditroi@atomki.hu
}

also measured along the whole range of the bombarding beam making possible to deduce not only the beam intensity but also the correction of the nominal beam energy in the stack. Measurement of the gamma spectra of the activated foils were carried out without chemical separation. The measurements have started a few hours after EOB in measurements at VUB and after one and half day at CYRIC.

The beam currents were deduced from the monitor reactions, the number of the target nuclei from the precise mass and surface determination of the target foil. The calculated energy degradation [40] of the incident beam were checked and corrected on the basis of the monitor reactions. To calculate the amount of produced radioisotopes the decay data were taken from the ENDSF data files [41].

To estimate the uncertainties of the cross sections the linearly contributing processes were taken into account by equal sensitivities [42]. The errors of non-linear parameters (time) were not considered, but their contribution is minimal compared to other processes. The typical total resulting errors are around $8-13 \%$. In the estimation of the uncertainty of the energy of the bombarding beam the medium plane of the target above the well known beam energy broadening the cumulative propagation of the errors in the energy of the primary beam and in the foil thickness were taken into account.

More detailed description of the used experimental techniques and of the method of data evaluation can be found in our earlier publications $[26,43]$.

\section{Model calculations}

The theoretical calculations were carried out by using the ALICE-IPPE code. This code is an ALICE-91 version modified by the Obninsk group [44]. The original ALICE code was developed by Blann [45] on the basis of equilibrium and pre-equilibrium reaction mechanisms. A comparison of the ALICE-IPPE calculations with the experimental data shows that this modified code describes well the proton induced reactions at low energies. In this work the prediction capability of the model for deuteron induced reactions was investigated, where the direct processes play more important roles. The calculations were done with an a priori parameter set, without 


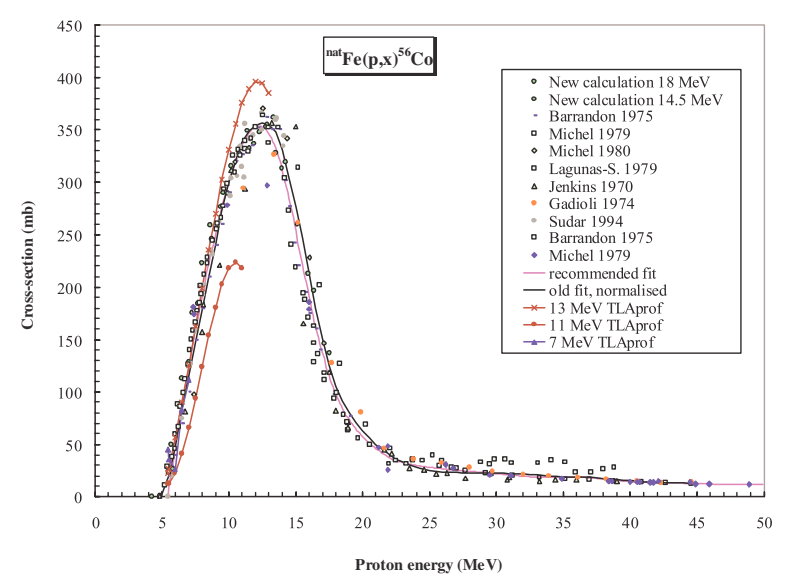

Fig. 1. Measured and fitted excitation function of the ${ }^{\text {nat }} \mathrm{Fe}(\mathrm{p}, \mathrm{x}){ }^{56} \mathrm{Co}$ nuclear reaction.

any adjustment for individual reaction. It has to be mentioned that the used code does not work with discrete levels and cannot separate the cross-section of the different isomeric states but it can calculate the sum.

\section{Results}

The aim of this study was to provide useful information and literature on the excitation functions of most common construction materials can be used for the nuclear wear measurements.

\subsection{Iron}

Iron is really the most common construction material. The radioisotopes produced from it are very suitable for the purposes of nuclear wear measurements. In figure 1 the measured and fitted excitation function of the proton induced nuclear reaction is shown. The isotope ${ }^{56} \mathrm{Co}$ has a suitable half-life $(77.1 \mathrm{~d})$ and strong enough gamma energies (most intense $\gamma$-line: $846.7 \mathrm{keV}$ ). As seen from figure 1 an irradiation below $14 \mathrm{MeV}$ proton energy can produce homogenous activity distribution in the upper 20 micrometers and linear as deep as 250 micrometers with measurable radiation intensity. By using non-vertical irradiation this activity can be concentrated into several micrometers making possible the so called nano-wear measurement.

In several cases it is necessary to investigate the wear of two ore more different parts, which are located so closed that the radiations coming from them cannot be separated/shielded. In this case a different isotope must be produced in the second part. Iron is very suitable for this method because an other "good" isotope, the ${ }^{57}$ Co (half-life: $271.8 \mathrm{~d}$; $\gamma$-lines: 122 and $136.4 \mathrm{keV}$ ) can also be effectively produced by deuteron irradiation.

As shown in figure 2 an irradiation under $9 \mathrm{MeV}$ deuteron energy produces similar results for ${ }^{57} \mathrm{Co}$ as in the former case was for ${ }^{56} \mathrm{Co}$. From the results in figures 1 and 2 one can deduce more useful data, i.e., the yield curves and the activity versus depth distribution. These data can be directly used for wear measurements even by industrial people (see figs. 3 and 4).

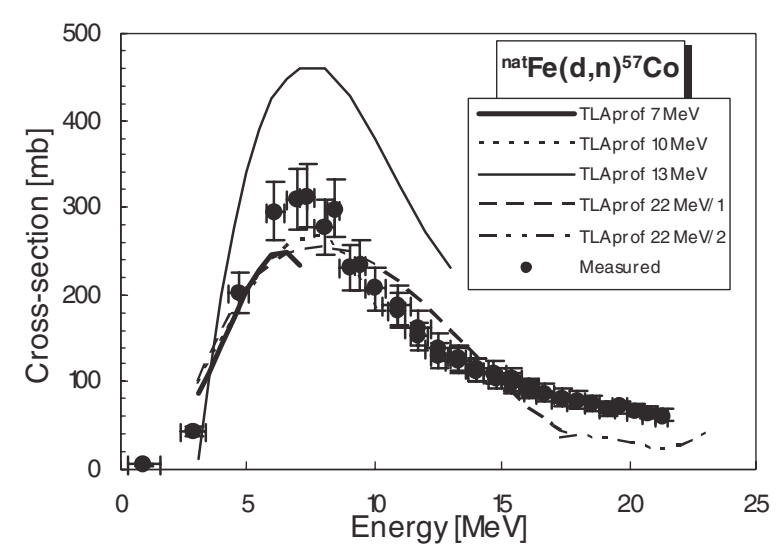

Fig. 2. Measured and fitted excitation function of the ${ }^{\text {nat }} \mathrm{Fe}(\mathrm{d}, \mathrm{x}){ }^{57} \mathrm{Co}$ nuclear reaction.

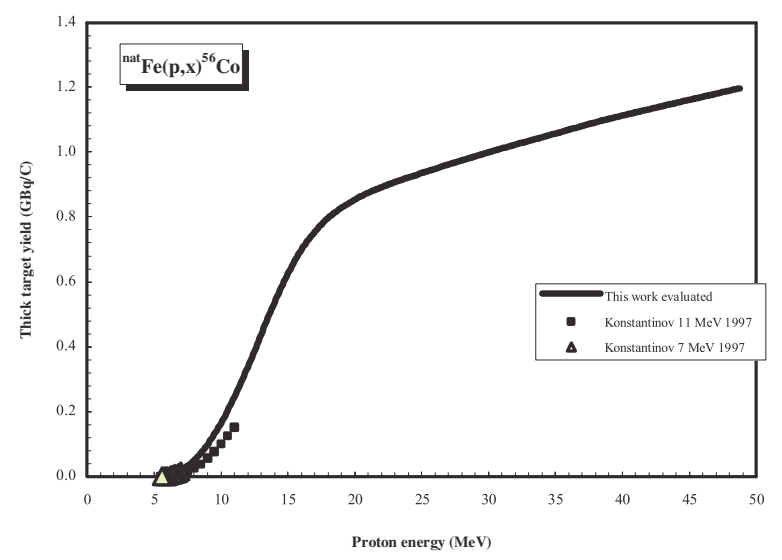

Fig. 3. Production yield of the ${ }^{56} \mathrm{Co}$ producing nuclear reaction on natural iron.

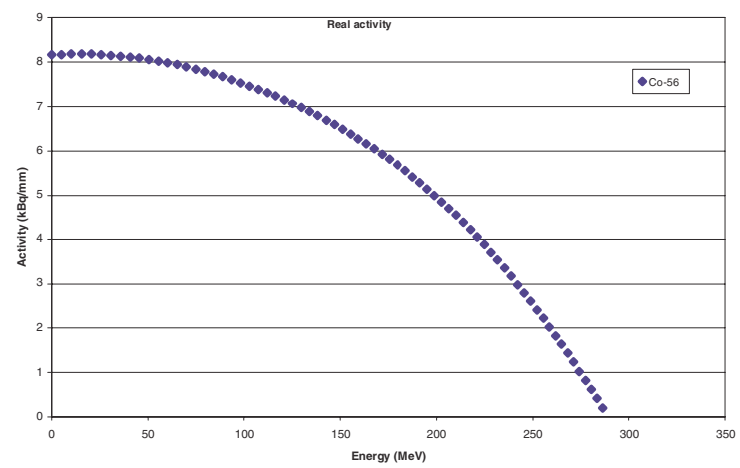

Fig. 4. The most useful activity distribution curve for ${ }^{56} \mathrm{Co}$.

\subsection{Other important construction elements}

Some samples do not contain iron as alloy component or it contains iron but a different isotope is necessary for the wear measurements. In this case other alloy components must be activated or the secondary implantation can be used. That's why we also measured and collected the data for the most important secondary elements.

From figure 5 it is clear and it is also seen from the previous figures that the TLAprof code gives only a raw 


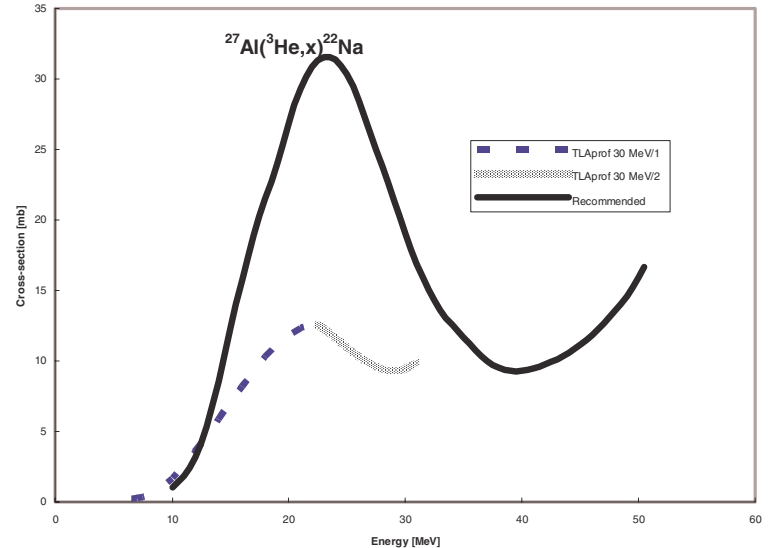

Fig. 5. Recommended excitation of the ${ }^{\text {nat }} \mathrm{Al}\left({ }^{3} \mathrm{He}, \mathrm{x}\right)^{22} \mathrm{Na}$ reaction compared with the results of TLApof code [46].

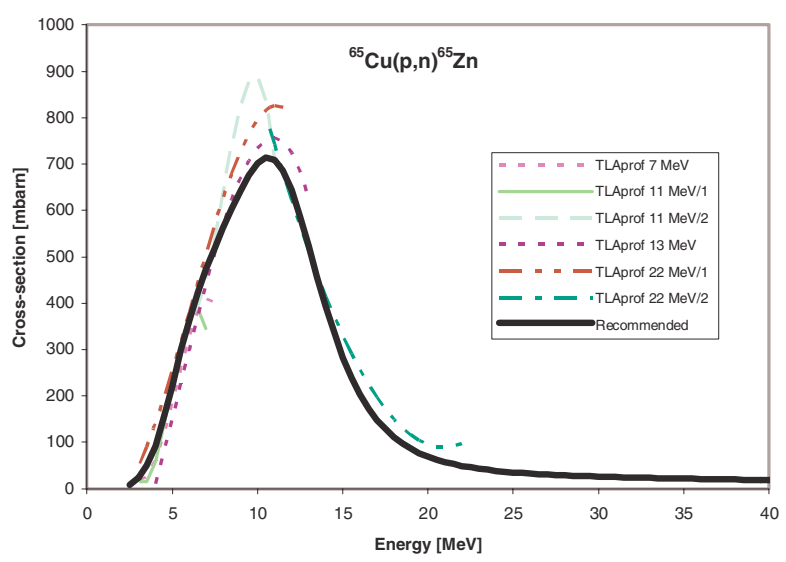

Fig. 6. Excitation function of the ${ }^{65} \mathrm{Cu}(\mathrm{p}, \mathrm{n})^{65} \mathrm{Zn}$ reaction.

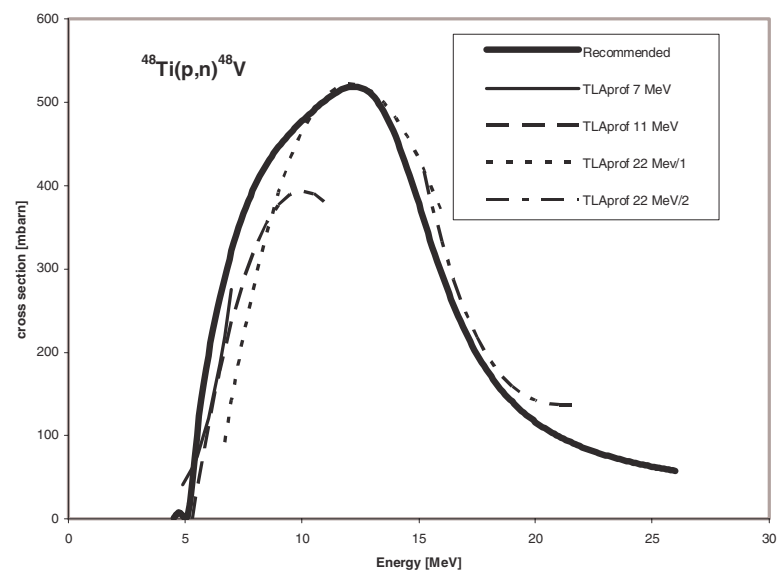

Fig. 7. Excitation function of the ${ }^{48} \mathrm{Ti}(\mathrm{p}, \mathrm{n})^{48} \mathrm{~V}$ nuclear reaction compared with the results of the TLAprof code [46].

estimation of the yield and in some cases such as the aluminium above gives wrong estimation. The activation with ${ }^{3} \mathrm{He}$ is very expensive and complicated, that's why one should consider the alternative methods, such as nuclear implantation or simply choose other alloy component if available.

As seen in figure 7, the TLAprof code gives an acceptable result for the estimation of the produced yield.

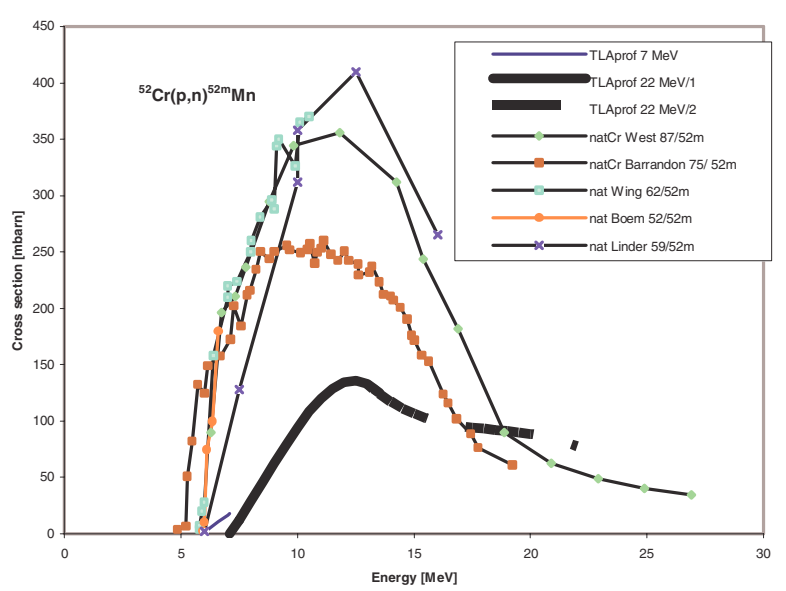

Fig. 8. Excitation function of ${ }^{52} \mathrm{Cr}(\mathrm{p}, \mathrm{n})^{52 \mathrm{~m}} \mathrm{Mn}$ nuclear reaction.

\section{Conclusion}

Our measurements and compilation show that the TLAprof code can be used for reliable yield estimation in several cases, but there are reactions where the results of TLAprof significantly differ from our results and/or the literature. It means that the establishment of a reliable database in this field is essential.

\section{References}

1. F. Ditrói, I. Mahunka, Nucl. Instrum. Meth. Phys. Res. B 113, 415 (1996).

2. F. Ditrói, I. Mahunka, Wear 219, 78 (1998).

3. I.O. Konstantinov, A.I. Leonov, V.I. Mikheev, Wear 141, 17 (1990).

4. G. Erdtmann, W. Soyka, The Gamma Rays of the Radionuclides (Verlag Chemie, Weinheim, New York, 1979).

5. Reaction Q-values and thresholds, Los Alamos National Laboratory, T-2 Nuclear Information Service, available from http://t2.lanl.gov.data/qtool.htm

6. Experimental Nuclear Reaction Data File (EXFOR), available from http://www-nds.iaea.or.at/exfor/

7. S.Y.F. Chu, L.P. Ekstrom, R.B. Firestone, WWW Table of Radioactive Isotopes, database version, 1999-02-28, from url: http://nucleardata.nuclear.lu.se/nucleardat.

8. F. Ditrói, A. Fenyvesi, S. Takács, F. Tárkányi, J. Bergman, S.-J. Heselius, O. Solin, Proceedings of the International Conference on Nuclear Data for Science and Technology, Gatlinburg, TN, USA, 9-13 May, 1994, edited by J.K. Dickens (La Grange Park, American Nuclear Society, Inc., 1994), p. 383.

9. F. Ditrói, S. Takács, F. Tárkányi, A. Fenyvesi, J. Bergman, S.-J. Heselius., O. Solin, Nucl. Instrum. Meth. Phys. Res. B 103, 389 (1995).

10. F. Ditrói, S. Takács, F. Tárkányi, I. Mahunka, Nucl. Instrum. Meth. Phys. Res. B 103, 412 (1995).

11. F. Ditrói, F. Tárkányi, M.A. Ali, Nucl. Instrum. Meth. Phys. Res. B 161, 172 (2000).

12. F. Ditrói, F. Tárkányi, M.A. Ali, L. Andó, S.-J. Heselius, Yu.N. Shubin, Z. Youxiang, M.G. Mustafa, Nucl. Instrum. Meth. Phys. Res. B 168, 33 (2000). 
13. T. Ido, A. Hermanne, F. Ditrói, Z. Szücs, I. Mahunka, F. Tárkányi, J. Nucl. Sci. Technol. 2, 1310 (2002).

14. T. Ido, A. Hermanne, F. Ditrói, Z. Szücs, I. Mahunka, F. Tárkányi, Nucl. Instrum. Meth. Phys. Res. B 194, 369 (2002).

15. F. Tárkányi, F. Ditrói, S. Takács, M. Al-Abyad, M.G. Mustafa, Yu.N. Shubin, Y. Zhuang, Nucl. Instrum. Meth. Phys. Res. B 196, 215 (2002).

16. F. Tárkányi, F. Ditrói, F. Szelecsényi, M. Sonck, A. Hermanne, Nucl. Instrum. Meth. Phys. Res. B 198, 11 (2002).

17. F. Tárkányi, F. Ditrói, S. Takács, F. Szelecsényi, A. Hermanne, M. Sonck, Nucl. Instrum. Meth. Phys. Res. B 207, 381 (2003).

18. F. Tárkányi, S. Takács, A. Hermanne, F. Ditrói, L. Andó, S.-J. Heselius., J. Bergman, Nucl. Instrum. Meth. Phys. Res. B 211, 22 (2003).

19. F. Tárkányi, F. Ditrói, S. Takács, Nucl. Instrum. Meth. Phys. Res. B 211, 312 (2003) .

20. F. Tárkányi, S. Takács, F. Szelecsényi, F. Ditrói, A. Hermanne, M. Sonck, Nucl. Instrum. Meth. Phys. Res. B 211, 319 (2003).

21. F. Tárkányi, A. Hermanne, S. Takács, F. Ditrói, A.I. Dityuk, Yu.N. Shubin, Nucl. Instrum. Meth. Phys. Res. B 217, 373 (2004).

22. F. Tárkányi, S. Takács, F. Ditrói, A. Hermanne, M. Sonck, Yu.N. Shubin, Nucl. Instrum. Meth. Phys. Res. B 217, 531 (2004).

23. F. Tárkányi, F. Ditrói, S. Takács, Gy. Csikai, A. Hermanne, M.S. Uddin, M. Hagiwara, M. Baba, Yu.N. Shubin, A.I. Dityuk, Nucl. Instrum. Meth. Phys. Res. B 226, 473 (2004).

24. F. Tárkányi, S. Takács, F. Ditrói, A. Hermanne, Yu.N. Shubin, A.I. Dityuk, Nucl. Instrum. Meth. Phys. Res. B 226, 490 (2004).

25. M.S. Uddin, M. Hagiwara, F. Tárkányi, F. Ditrói, M. Baba, Appl. Radiat. Isot. 60911 (2004).

26. M.S. Uddin, M. Hagiwara, N. Kawata, T. Itoga, N. Hirayabashi, M. Baba, F. Tárkányi, F. Ditrói, Gy. Csikai, J. Nucl. Sci. Technol. 4, 160 (2004).

27. F. Tárkányi, F. Ditrói, Gy. Csikai, S. Takács, M.S. Uddin, M. Hagiwara, M. Baba, Yu.N. Shubin, A.I. Dityuk, Appl. Radiat. Isot. 62, 73 (2005).

28. F. Tárkányi, B. Király, F. Ditrói, S. Takács, Gy. Csikai, A. Hermanne, M.S. Uddin, M. Hagiwara, M. Baba, T. Ido, Yu.N. Shubin, A.I. Dityuk, Nucl. Instrum. Meth. Phys. Res. B 239, 293 (2005).

29. M.S. Uddin, M. Hagiwara, M. Baba, F. Tárkányi, F. Ditrói, Appl. Radiat. Isot. 62, 533 (2005).
30. M.S. Uddin, M. Hagiwara, M. Baba, F. Tárkányi, F. Ditrói, Appl. Radiat. Isot. 63, 367 (2005).

31. F. Ditrói, F. Tárkányi, Gy. Csikai, M.S. Uddin, M.M. Hagiwara, M. Baba, Yu.N. Shubin, S.F. Kovalev, Nucl. Instrum. Meth. Phys. Res. B 243, 20 (2006).

32. F. Ditrói, S. Takács, F. Tárkányi, M. Reichel, M. Scherge, A. Gervé, Wear 261, 1397 (2006).

33. A. Hermanne, F. Tárkányi, F. Ditrói, S. Takács, R.A. Rebeles, M.S. Uddin, M. Hagiwara, M. Baba, Yu.N. Shubin, S.F. Kovalev, Nucl. Instrum. Meth. Phys. Res. B 247, 180 (2006).

34. F. Tárkányi, B. Király, F. Ditrói, S. Takács, Gy. Csikai, A. Hermanne, M.S. Uddin, M. Hagiwara, M. Baba, T. Ido, Yu.N. Shubin, S.F. Kovalev, Nucl. Instrum. Meth. Phys. Res. B 245, 379 (2006).

35. F. Tárkányi, B. Király, F. Ditrói, S. Takács, Gy. Csikai, A. Hermanne, M.S. Uddin, M. Hagiwara, M. Baba, Yu.N. Shubin, S.F. Kovalev, Nucl. Instrum. Meth. Phys. Res. B 247, 210 (2006).

36. F. Tárkányi, S. Takács, F. Szelecsényi, F. Ditrói, A. Hermanne, M. Sonck, Nucl. Instrum. Meth. Phys. Res. B 252, 160 (2006).

37. M.S. Uddin, M. Baba, M. Hagiwara, F. Tárkányi, F. Ditrói, S. Takács, A. Hermanne, Appl. Radiat. Isot. 64, 1013 (2006).

38. F. Ditrói, F. Tárkányi, S. Takács, I. Mahunka, Gy. Csikai et al., Radioanal. Nucl. Chem. (in press).

39. F. Tárkányi, F. Ditrói, S. Takács et al., Investigation of excitation functions of deuteron induced nuclear reactions on lead (Abstr: p. 278) MARC-VII Methods and Applications of Radioanalytical Chemistry, Kailua-Kona, USA, 3-7 April, 2006.

40. H.H. Andersen, J.F. Ziegler, Hydrogen Stopping Powers and Ranges in all Elements, Vol. 3, Handbook of Stopping Crosssections or Energetic Ions and Elements (Pergamon Press, New York, 1997).

41. NuDat, http://www.nndc.bnl.gov/.

42. Guide to Expression of Uncertainty in Measurement (1993). International Organisation for Standardization, Geneva, ISBN 92-67-10188-9.

43. S. Takács, F. Tárkányi, M. Sonck, A. Hermanne, Nucl. Instrum. Meth. B 198, 183 (2002).

44. A. I. Dityuk, A.Yu. Konobeyev, V.P. Lunev, Yu.N. Shubin, New version of the advanced computer code ALICE-IPPE, Report INDC (CCP)-410, IAEA, Vienna, 1998.

45. M. Blann, LLNL Report, UCRL-JC-109052, 1991.

46. G. Wallace, Calculation of depth profile for thin layer activation, Client Report, 62891H 11, prepared for IAEA Contract C3-544, project RAS/8/078, March 1999 (unpublished). 